

RESEARCH ARTICLE

\title{
Influence of Operator's Experience on the Shaping Ability of Protaper Universal and Waveone Systems: A Comparative Study on Simulated Root Canals
}

\author{
Giuseppe Troiano ${ }^{1, *}$, Mario Dioguardi ${ }^{1}$, Armando Cocco ${ }^{1}$, Giovanni Giannatempo ${ }^{1}$, Luigi Laino ${ }^{1}$, \\ Domenico Ciavarella ${ }^{1}$, Elio Berutti ${ }^{2}$ and Lorenzo Lo Muzio ${ }^{1}$ \\ ${ }^{I}$ Department of Clinical and Experimental Medicine, University of Foggia, Foggia, Italy \\ ${ }^{2}$ Department of Endodontics, University of Turin Dental School, Turin, Italy
}

Received: February 24, 2016

Revised: July 20, 2016

Accepted: September 02, 2016

Abstract:

\section{Objective:}

To assess the influence of operator experience on: shaping and centering ability, mean preparation time and presence of canal aberrations of ProTaper Universal and WaveOne systems on simulated root canals.

\section{Materials and Methods:}

Sixty S-shaped canals in resin blocks were assigned to four groups ( $\mathrm{n}=15$ for each group). Group1 (Experienced operator, ProTaper), Group2 (Experienced operator, WaveOne), Group3 (Inexperienced operator, ProTaper), Group4 (Inexperienced operator, WaveOne). Photographic method was used to record pre- and post-instrumentations images. After superimposition, it has been evaluated presence of canal aberrations and differences in shaping and centering ability between groups.

\section{Results:}

WaveOne system produced a lower amount of canal aberrations both in the hand of expert than inexpert operators. However, a WaveOne instrument breakage occurred in the hands of an inexperienced operator. No differences have been found in the evaluation of shaping ability with both systematics. Operator's experience doesn't influence the shaping ability of ProTaper and WaveOne systems.

\section{Conclusion:}

Experience factor could influence the centering ability in the use of both the systematics. However, WaveOne Primary reduce the mean preparation time and the presence of canal aberrations.

Keywords: Centering ability, Endodontic, ProTaper, Reciprocating, Shaping ability, WaveOne.

\section{INTRODUCTION}

A correct shaping is one of the most important goal to achieve success in endodontic treatment. Ni-Ti instruments allowed a cutting easier way to prepare root canals and thanks to their elastic properties allow a reduction of the mean time of shaping and an improvement of the centering ability [1]. Ni-Ti systematic differ for: taper, tip size, blade pitch, type of rotary motion and instruments number [2]. The use of largely Ni-Ti rotary systems is based on Crown-Down

\footnotetext{
* Address correspondence to this author at the Department of Clinical and Experimental Medicine, University of Foggia Via Rovelli, 50, 71122 Foggia, Italy; Tel: +0039 0881 588090; Fax: +0039 0881 588081; E-mail: giutroiano@gmail.com
} 
concepts that allow a reduction of intracanal friction and should decrease the risk of intracanal fracture [3], this is also due to the presence of non cutting tip that reduce the possibility of taper lock [4]. The ProTaper Universal system (PTU) (Dentsply Maillefer, Ballaigues, Switzerland) involves the use of instruments having a convex triangular cross-sectional design with multiple taper size [5]. The first two instruments (shaping set) primarily shape the coronal and middle part of the canal, while the last tools (finishing set) work in the apical region [6]. The need to reduce time of shaping combined with a higher ease of use has led to the development of single file systems. These files are manufactured with M-Wire alloy which allows a better flexibility and improve resistance to cyclic fatigue [7]. Besides, this system involves the use with reciprocating motion, which decreases instrument stress and apical debris [8]. However, data on apical debris contrasting with results of other studies, which suggest that increase (correct the ward to increase) of apical debris was caused by the counterclockwise movement [9]. WaveOne is a single file system with a modified convex triangular cross-section at the tip end and a convex triangular cross-section, similar to ProTaper, at the coronal end [10]. The purpose of this study was to assess the influence of operator experience on the presence of aberrations and shaping ability when using ProTaper (multi instruments system) and WaveOne (single file system) in S-shape simulated root canals.

\section{MATERIALS AND METHODS}

\section{Shaping Procedures}

A number of 15, S-shaped ISO 150.02 taper endo training blocks (Dentsply Maillefer), were assigned to each group for a total of 60 . Although these samples presenting qualitative differences with teeth, they represent a valid tool for in vitro evaluations because they permit an easier standardization and comparison of different shaping methods [11]. Groups 1 and 2 were shaped by an expert operator, postgraduate in endodontics with more of ten years experience, while, an inexperienced operator, a student in the last year of study, with poor endodontic experience performed shaping in Groups 3-4 [12]. A first survey of canals has been made with \# $10 \mathrm{~K}$ file to assess the working length (WL), after that the glide path was achieved with PathFile 1, 2, and 3 (Dentsply Maillefer) at the WL. Subsequently, samples in groups 1 and 3 were shaped with ProTaper system (S1-S2-F1-F2), whilst groups 2 and 4 were shaped with WaveOne Primary reciprocating file in order to have in each method a tip size of $0.25 \mathrm{~mm}$ [13]. A dedicated shaping program has been used for the utilization of each single file with parameters suggested by manufacturers (X-Smart; Dentsply Maillefer). Before use, each instrument was lubricated with Glyde (Dentsply Maillefer), whilst a rinse with $2.5 \%$ $\mathrm{NaOCl}$ was made after the use of each instrument. A set of new instruments was used for the shaping of each resin block. The preparation time has been recorded for each simulated canal from the end of glide path to the reaching the WL with the final file.

\section{Data Recording}

Pre- and post- instrumentation images were recorded with a digital camera (Canon 1100D, Tokyo Japan, ISO 100, $\mathrm{f}$ $18,1 / 60 \mathrm{~s})$ at a fixed points and magnification. To decrease movements during shooting photo has been used an at distance activation command, and the camera was mounted on a stable support. Furthermore, reference points were placed on the specimens to facilitate the subsequent superimposition. This last one has been carried out with the use of dedicated imaging software (GIMP 2.8, Free Software Foundation, Boston, USA). After that, superimposed images have been loaded on Autocad 2013 (Autodesk Inc, San Rafael, USA) software to perform shaping analysis (Fig. 1). Amount of resin removed from the inner and outer aspect of the canal has been recorded at 1 to $9 \mathrm{~mm}(1 \mathrm{~mm}$ for each step) from the apex for a total of 18 measurements for each canal (Fig. 1). All measurements were carried out at a right angle to the mean axis of the pre-instrumental canal [14]. Centering ability was evaluated at each point subtracting the amount of resin removed from the inner part to that removed from the outer aspect of the canal. While width shaping has been calculated adding these two measurements [15].

\section{Canal Aberrations and Instrument Fracture}

Presence of canal aberrations has been evaluated according to the parameters of Thompson and Dummer [16] by a third operator blinded for this study. Thanks to photographic evaluation has been recorded the possible presence of: elbow, apical zip, perforation and danger zone. In addition, we evaluated if experience factor could increase the rate of instrument fracture when using ProTaper or WaveOne systems. 




Fig. (1). Positions of measurement have been detected by nine concentric circles with center in the apex .

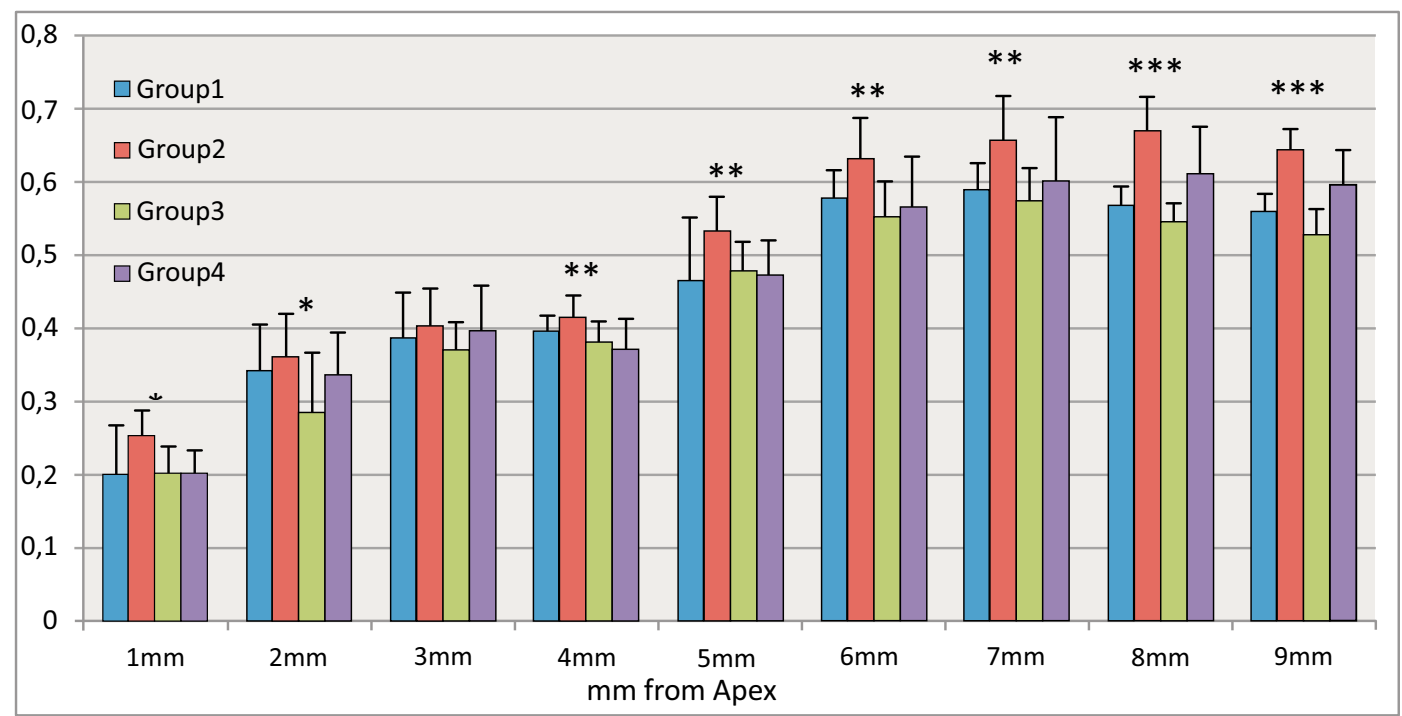

Fig. (2). Total amount of resin removed in S-shaped canals.

\section{Statistical Analysis}

Data have been analyzed using GraphPad Prism software 6.00 (GraphPad Prism Software, San Diego, CA,USA) by an expert in statistical analysis. Statistical significance between different groups was determined by one-way ANOVA and Tukey test.

\section{RESULTS}

\section{Preparation Time}

The mean preparation time, employed with the use of the two systematic, for each group has been reported in Table 1. According with these data, WaveOne system determines a reduction of time of shaping both in expert than in inexpert operator compared with ProTaper system.

\section{Presence of Canal Aberrations and Instrument Failures}

The results of canal aberrations are summarized in Table 2. ProTaper groups showed a higher tendency to produce canal aberrations than WaveOne groups. However, an event of instrument breakage was found only in Group 4, while this event has not been reported in the remaining groups. 
Table 1. Mean preparation time have been expressed as mean $+/$ - standard deviations. Data are expressed in seconds.

\begin{tabular}{|c|c|c|}
\hline & Mean & SD \\
\hline Group 1 & $228 \mathrm{~s}$ & $35.8 \mathrm{~s}$ \\
\hline Group 2 & $44.8 \mathrm{~s}$ & $4.7 \mathrm{~s}$ \\
\hline Group 3 & $405.4 \mathrm{~s}$ & $47.9 \mathrm{~s}$ \\
\hline Group 4 & $110 \mathrm{~s}$ & $36.6 \mathrm{~s}$ \\
\hline
\end{tabular}

Table 2. Incidence of canal aberrations on S-shape simulated root canals.

\begin{tabular}{|c|c|c|c|c|c|c|}
\hline Aberration tipe & Apical Zip & Elbow & Ledges & Perforation & Danger zone & Instrument Breakage \\
\hline Group 1 & 2 & 1 & - & - & - & - \\
\hline Group 2 & - & - & - & - & - & - \\
\hline Group 3 & 3 & 2 & 1 & 1 & - & - \\
\hline Group 4 & 1 & 1 & - & - & - & 1 \\
\hline
\end{tabular}



Fig. (3). Centering ability in the four groups. ( $\left.{ }^{\mathrm{P}}<0.05 ; * * \mathrm{P}<0.01 ; * * * \mathrm{P}<0.001\right)$.

Table 3. Analysis of the amount resin removed from the inner and outer aspect of the canal at nine points level from the apex. (*P $<0.05 ; * * \mathrm{P}<0.01 ; * * * \mathrm{P}<0.001)$.

\begin{tabular}{|c|c|c|c|c|c|c|c|c|c|c|c|c|c|c|c|c|c|c|}
\hline & \multicolumn{9}{|c|}{ Inner canal side ( $\mathrm{mm}$ from the apex) } & \multicolumn{9}{|c|}{ Outer canal side ( $\mathrm{mm}$ from the apex) } \\
\hline & 1 & 2 & 3 & 4 & 5 & 6 & 7 & 8 & 9 & 1 & 2 & 3 & 4 & 5 & 6 & 7 & 8 & 9 \\
\hline \multicolumn{19}{|l|}{ Group 1} \\
\hline Mean & 0.105 & 0.260 & 0.310 & 0.235 & 0.143 & \begin{tabular}{|l|l|}
0.115 \\
\end{tabular} & 0.142 & 0.212 & 0.281 & 0.096 & 0.082 & 0.078 & 0.161 & 0.323 & 0.446 & 0.448 & 0.335 & 0.277 \\
\hline SD & 0.062 & 0.075 & 0.066 & 0.032 & 0.027 & 0.027 & 0.044 & 0.047 & 0.037 & 0.051 & 0.016 & 0.025 & 0.026 & 0.079 & 0.034 & 0.066 & 0.061 & 0.048 \\
\hline \multicolumn{19}{|l|}{ Group 2} \\
\hline Mean & 0.121 & 0.241 & 0.290 & 0.238 & 0.187 & \begin{tabular}{|l|l|}
0.190 \\
\end{tabular} & 0.226 & 0.286 & 0.314 & 0.132 & 0.117 & 0.113 & 0.179 & 0.347 & 0.441 & 0.432 & 0.387 & 0.329 \\
\hline SD & 0.031 & 0.046 & 0.053 & 0.045 & 0.068 & 0.103 & 0.106 & 0.089 & 0.068 & 0.034 & 0.047 & 0.048 & 0.036 & 0.062 & 0.132 & 0.129 & 0.108 & 0.082 \\
\hline \multicolumn{19}{|l|}{ Group 3} \\
\hline Mean & 0.075 & 0.219 & 0.311 & 0.248 & 0.134 & 0.107 & 0.158 & 0.222 & 0.290 & 0.126 & 0.066 & 0.06 & 0.132 & 0.342 & 0.445 & 0.416 & 0.325 & 0.237 \\
\hline SD & 0.042 & 0.087 & 0.042 & 0.039 & 0.034 & \begin{tabular}{|l|}
0.029 \\
\end{tabular} & 0.029 & 0.029 & 0.027 & 0.024 & 0.023 & 0.016 & 0.047 & 0.038 & 0.047 & 0.045 & 0.024 & 0.017 \\
\hline \multicolumn{19}{|l|}{ Group 4} \\
\hline Mean & 0.067 & 0.023 & 0.328 & 0.258 & 0.163 & 0.142 & 0.196 & 0.275 & 0.330 & 0.136 & 0.098 & 0.067 & 0.112 & 0.309 & 0.422 & 0.408 & 0.335 & 0.265 \\
\hline SD & 0.034 & 0.060 & 0.067 & 0.046 & 0.049 & 0.048 & 0.071 & 0.069 & 0.053 & 0.034 & 0.016 & 0.013 & 0.024 & 0.047 & 0.071 & 0.082 & 0.079 & 0.068 \\
\hline P-value & ** & **** & - & - & * & ** & ** & ** & * & * & $* * *$ & $* * *$ & *** & - & - & - & - & *** \\
\hline
\end{tabular}




\section{Amount of Resin Removed}

The amount of resin removed from the interior and exterior wall of the channel was measured from 1 to 9 millimeters to the apex and is summarized in Table 3. Adding, the internal and external measurements to each millimeter, the total amount of resin removed was obtained at each measurement point (Fig. 2). From the graph it can see that the experienced operator tends to shape more the apical area (1 to $3 \mathrm{~mm}$ from the apex) respect to the inexpert operator. The difference is significant regarding use of systematic WaveOne $(p<0,05)$

\section{Centering Ability}

The centering ability was evaluated between groups and reported in Fig. (3). The difference was statistically significant only at levels 3 and 4 from the apex. At these levels the experience factor has allowed to obtain a better centering with both systematic. We noticed that WaveOne got skill centering best of systematic ProTaper, but the differences are not significant report in the apical part of the canal.

\section{DISCUSSION}

The shaping of the root canal system is one of the most important steps in endodontics, in order to create a path suitable for the subsequent action of irrigants. Niti alloy allows a simpler and easier action thanks to its elastic properties. A lot of instrumentation techniques have been developed providing clinicians various options for a correct root canal shaping. These systems differ among themselves for: cutting section, instruments' number, subtype of Niti alloy and dynamics of motion. However poor studies have evaluated the influence of operator experience on the shaping ability of different Niti systems [17]. For this reason we performed a comparison of a multistep rotational system (ProTaper) with a single-file reciprocating system (WaveOne) in the hands of operators with different experience. In this study we evaluated the shaping and centering ability, presence of canal aberrations and time of preparation on simulated root canals. Simulated root canals allow a direct visualization and represent a valid tool for comparative analysis [11]. Results of our analysis revealed a reduction of time of preparation with WaveOne single file both in expert and inexpert operator. In addition, single file reciprocating system strongly reduce the possibility of canal aberrations (Group 3 vs Group 4), these data accord to others authors about a lower presence of aberrations and cracks using reciprocating than rotational systems [18]. However, one instrument breakage occurred in the WaveOne inexpert group, this is in contrast with the results of previously studies in which no instrument breakage occurred with the use of reciprocating WaveOne file [19]. Analysis on centering ability was performed after photographic superimposition, our data showed no differences between groups with the same experience factor rate. These results accord to previously study in which no differences have been found between centering abilities of ProTaper and WaveOne systems [20]. However, comparing these parameters with Tukey test, we found a statistically difference in centering ability $(\mathrm{p}<0,05)$ between groups 2 and 4 at 3-4 mm from the apex. Evaluating the amount of resin removed showed no difference in the shaping ability with ProTaper System suggesting no influence of operator experience in the management of this systematic. In the comparison of WaveOne groups with different experience statistically significant difference has been found in the use of this system from 4 to $9 \mathrm{~mm}$. Data revealed that inexperienced operator tends to less prepare the apical portion of the canal (1 to $3 \mathrm{~mm}$ ), because of a worse respect of WL, while he performed an higher amount of shaping in the coronal aspect ( 7 to $9 \mathrm{~mm}$ ), probably due to execution of brushing movements.

\section{CONCLUSION}

Under the conditions and limitations of this study, operator's experience doesn't influence the shaping ability of ProTaper and WaveOne systems. Experience factor could influence the centering ability in the use of both the systematics at the apical portion (3-4 mm). However, WaveOne system reduced the mean preparation time and the presence of canal aberrations. In addition, instrument breakage might occurred as a result of improper use of WaveOne file in the hands of an inexperienced operator, for these reasons, performing a glyde-path could help clinicians to reduce iatrogenic errors.

\section{CONFLICT OF INTEREST}

The authors confirm that this article content has no conflict of interest. 


\title{
ACKNOWLEDGEMENTS
}

\author{
Declared none.
}

\section{REFERENCES}

[1] Thompson SA, Dummer PM. Shaping ability of ProFile.04 Taper Series 29 rotary nickel-titanium instruments in simulated root canals. Part 2. Int Endod J 1997; 30(1): 8-15. [http://dx.doi.org/10.1111/j.1365-2591.1997.tb01092.x] [PMID: 9477789]

[2] Ounsi HF, Franciosi G, Paragliola R, et al. Comparison of two techniques for assessing the shaping efficacy of repeatedly used nickeltitanium rotary instruments. J Endod 2011; 37(6): 847-50. [http://dx.doi.org/10.1016/j.joen.2011.02.030] [PMID: 21787503]

[3] Peters OA. Current challenges and concepts in the preparation of root canal systems: a review. J Endod 2004; 30(8): 559-67. [http://dx.doi.org/10.1097/01.DON.0000129039.59003.9D] [PMID: 15273636]

[4] Berutti E, Paolino DS, Chiandussi G, et al. Root canal anatomy preservation of WaveOne reciprocating files with or without glide path. J Endod 2012; 38(1): 101-4. [PMID: 22152630]

[5] Bergmans L, Van Cleynenbreugel J, Beullens M, Wevers M, Van Meerbeek B, Lambrechts P. Progressive versus constant tapered shaft design using NiTi rotary instruments. Int Endod J 2003; 36(4): 288-95. [http://dx.doi.org/10.1046/j.1365-2591.2003.00650.x] [PMID: 12702124]

[6] González Sánchez JA, Duran-Sindreu F, de Noé S, Mercadé M, Roig M. Centring ability and apical transportation after overinstrumentation with ProTaper Universal and ProFile Vortex instruments. Int Endod J 2012; 45(6): 542-51. [http://dx.doi.org/10.1111/j.1365-2591.2011.02008.x] [PMID: 22264187]

[7] Pedulla E, Lo Savio F, Boninelli S, et al. Influence of cyclic torsional preloading on cyclic fatigue resistance of nickel - titanium instruments Int Endod J 2015; 48(11): 1043-50.

[http://dx.doi.org/10.1111/iej.12400] [PMID: 25353957]

[8] De-Deus G, Brandão MC, Barino B, Di Giorgi K, Fidel RA, Luna AS. Assessment of apically extruded debris produced by the single-file ProTaper F2 technique under reciprocating movement. Oral Surg Oral Med Oral Pathol Oral Radiol Endod 2010; 110(3): 390-4. [http://dx.doi.org/10.1016/j.tripleo.2010.04.020] [PMID: 20727500]

[9] Bürklein S, Schäfer E. Apically extruded debris with reciprocating single-file and full-sequence rotary instrumentation systems. J Endod 2012; 38(6): 850-2.

[http://dx.doi.org/10.1016/j.joen.2012.02.017] [PMID: 22595125]

[10] Bonessio N, Pereira ES, Lomiento G, et al. Validated finite element analyses of WaveOne Endodontic Instruments: a comparison between MWire and NiTi alloys. Int Endod J 2014.

[PMID: 24923193]

[11] Lim KC, Webber J. The validity of simulated root canals for the investigation of the prepared root canal shape. Int Endod J 1985; 18(4): 240-6. [http://dx.doi.org/10.1111/j.1365-2591.1985.tb00450.x] [PMID: 3865899]

[12] Mandel E, Adib-Yazdi M, Benhamou LM, Lachkar T, Mesgouez C, Sobel M. Rotary Ni-Ti profile systems for preparing curved canals in resin blocks: influence of operator on instrument breakage. Int Endod J 1999; 32(6): 436-43. [http://dx.doi.org/10.1046/j.1365-2591.1999.00239.x] [PMID: 10709491]

[13] Berutti E, Chiandussi G, Paolino DS, et al. Canal shaping with WaveOne Primary reciprocating files and ProTaper system: a comparative study. J Endod 2002; 38(4): 505-9.

[14] Schäfer E, Lohmann D. Efficiency of rotary nickel-titanium FlexMaster instruments compared with stainless steel hand K-Flexofile--Part 1. Shaping ability in simulated curved canals. Int Endod J 2002; 35(6): 505-13. [http://dx.doi.org/10.1046/j.1365-2591.2002.00513.x] [PMID: 12190907]

[15] Yang GB, Zhou XD, Zhang H, Wu HK. Shaping ability of progressive versus constant taper instruments in simulated root canals. Int Endod J 2006; 39(10): 791-9. [http://dx.doi.org/10.1111/j.1365-2591.2006.01151.x] [PMID: 16948665]

[16] Thompson SA, Dummer PM. Shaping ability of Hero 642 rotary nickel-titanium instruments in simulated root canals: Part 1. Int Endod J 2000; 33(3): 248-54. [http://dx.doi.org/10.1046/j.1365-2591.2000.00287.x] [PMID: 11307443]

[17] Capar ID, Arslan H. A review of instrumentation kinematics of engine-driven nickel titanium instruments. Int Endod J 2015. [PMID: 25630977]

[18] Kansal R, Rajput A, Talwar S, Roongta R, Verma M. Assessment of dentinal damage during canal preparation using reciprocating and rotary files. J Endod 2014; 40(9): 1443-6. [http://dx.doi.org/10.1016/j.joen.2014.02.015] [PMID: 25146029]

[19] Generali L, Righi E, Todesca MV, Consolo U. Canal shaping with WaveOne reciprocating files: influence of operator experience on instrument breakage and canal preparation time. Odontology / Soc Nippon Dental Uni 2014; 102(2): 217-2. 
[http://dx.doi.org/10.1007/s10266-013-0118-1]

[20] McRay B, Cox TC, Cohenca N, Johnson JD, Paranjpe A. A micro-computed tomography-based comparison of the canal transportation and centering ability of ProTaper Universal rotary and WaveOne reciprocating files. Quintessence Int 2014; 45(2): 101-8. [PMID: 24389561]

(C) Troiano et al.; Licensee Bentham Open

This is an open access article licensed under the terms of the Creative Commons Attribution-Non-Commercial 4.0 International Public License (CC BY-NC 4.0) (https://creativecommons.org/licenses/by-nc/4.0/legalcode), which permits unrestricted, non-commercial use, distribution and reproduction in any medium, provided the work is properly cited. 